Max-Planck-Institut für demografische Forschung

Max Planck Institute for Demographic Research

Doberaner Strasse 114 - D-18057 Rostock - GERMANY

Tel +49 (0) 3812081 - 0; Fax +49 (0) 3812081 - 202;

http://www.demogr.mpg.de

MPIDR WORKING PAPER WP 2001-011

APRIL 2001

\title{
Childbearing patterns of foreign-born women in Sweden
}

Gunnar Andersson (andersson@demogr.mpg.de)

This working paper has been approved for release by: Jan M. Hoem (hoem@ demogr.mpg.de)

Head of the Laboratory of Contemporary European Fertility and Family Dynamics.

(C) Copyright is held by the authors.

Working papers of the Max Planck Institute for Demographic Research receive only limited review. Views or opinions expressed in working papers are attributable to the authors and do not necessarily reflect those of the Institute. 


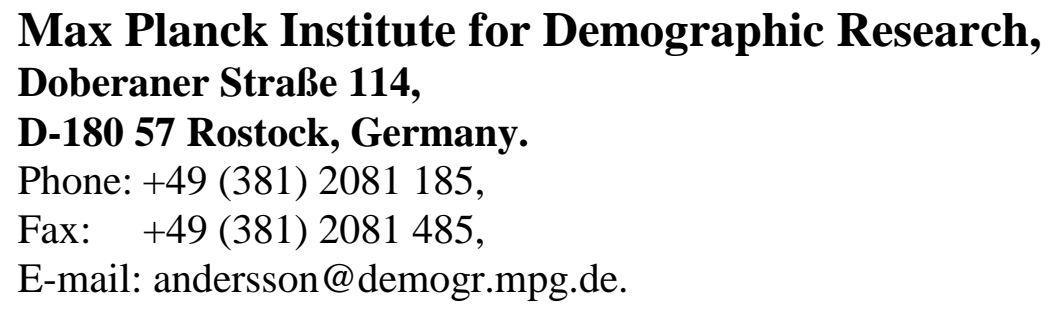

GA, 19 April 2001

\title{
Childbearing patterns of foreign-born women in Sweden
}

\author{
by Gunnar Andersson
}

\begin{abstract}
In this paper, we present an investigation of patterns in childbearing among foreign-born women in Sweden from the early 1960s and onwards. It is performed in a similar way as a previous study by the author who analyzed childbearing patterns of Swedish-born women in that country by applying event-history techniques to population-register data. We base our study on the longitudinal information on childbearing and migration of 446.000 women born abroad who had ever lived in Sweden before the end of 1999 . We display period trends in fertility by birth order for some aggregated groups of foreign-born women and find that developments over time have been quite similar for Swedish- and foreign-born women but that there exist important differences in levels of childbearing intensities between women stemming from different countries. When we examine patterns in childbearing by time since migration to Sweden, we find that such differences in most cases are due to the fact that immigrants tend to display higher levels of childbearing shortly after immigration. We conclude that migration and family building in many cases are interrelated processes and that it is always important to account for time since migration when fertility of immigrants is studied.
\end{abstract}




\section{Background}

Fertility in Sweden has fluctuated fairly strongly during the last four decades (see Hoem and Hoem, 1996, for a discussion). Andersson (1999) presents period trends in standardized first-, second-, third-, and fourth-birth rates in Sweden of women born in that country but no such detailed analysis of patterns in childbearing has yet been performed for the foreign-born population. Nevertheless, by the end of the 1990s, around 17 percent of all newborn children in Sweden were delivered by women born in another country so it should by now be of major interest to also examine the childbearing behavior of the foreign-born. This is necessary in order to properly understand observed changes in aggregate fertility pertaining to the nation as a whole. In addition, such an examination will provide valuable insights about the various processes of fertility change that are related to the event of an international migration.

Tabulations of numbers of births and fertility rates by age and country of origin are available at Statistics Sweden (see, e.g., SCB, 1996, Table 3.14 and Table 3.18). Such tabulations might reveal some features of fertility patterns as they appear in Total and Age-Specific Fertility Rates of women stemming from various countries. In most cases, however, it is hard to see whether these rates seem to be correlated with the TFR of Sweden or with the TFR of specific countries of origin - or with any of the two. Such measures simply are too crude for a proper understanding of the fertility dynamics of the continuously changing population of foreign-born women.

In this study, we use a new data set that has been derived at Statistics Sweden from the population registers of that country. By linking all children ever living in Sweden from the 1960s onwards to their mothers, it has been possible to derive longitudinal histories of childbearing also of immigrant women and, consequently, to track the parity-specific birth behavior of these women. This means that we now can perform a more sophisticated longitudinal analysis of the childbearing of the foreignborn female population, such as that done by Andersson (1999) for the Swedish-born population. Our data source allows us to study various aspects of the childbearing behavior of the very heterogeneous group of women stemming from countries outside Sweden. We can, for example, study the possible impact of the migration event on the fertility of immigrants. 
In the next section, we proceed with a presentation of ideas from previous research on fertility of immigrants in other countries than Sweden before we describe our data in a third section, present our results in Sections 4-6, and wind up with a brief discussion in our final section.

\section{Previous research on fertility of immigrants and outline of this study}

While not much is written about childbearing patterns of immigrants in Sweden, there exists a large body of literature on the fertility of recent immigrants in the U.S. Much of this literature has focused on the fertility of the Hispanic population in that country (see, e.g., Bean and Tienda, 1987), coming from high-fertility countries like Mexico (Bean and Swicegood, 1985) or Puerto Rico (Landale and Hauan, 1996), but attention has of course also been given to the childbearing-behavior of other immigrant groups like, for example, the Chinese (Sean-Shong and Saenz, 1997). Such studies have most often been based on census data and the same holds for related studies in other "New World" countries, like Australia (Abbasi-Shavazi and McDonald, 2000), and Canada (Ng and Nault, 1997).

In overseas countries, immigration has a more longstanding history than in Sweden and elsewhere in Europe. Many studies from the U.S. thus also deals with the childbearing behavior of minority groups who have lived there for several generations (see, e.g., Goldscheider and Uhlenberg, 1968). Such studies are relatively easy to perform there since American censuses classify people according to their ethnic or racial group. No such registration of ethnicity exists in Sweden and the same holds for the rest of Western Europe with the notable exception of Great Britain (Coleman and Salt, 1996). Large-scale immigration is still quite a "recent" phenomenon in this part of the world so it might still be more relevant to examine short-term changes in the behavior of immigrants than the more long-term adjustments that might occur in various population groups. In the present paper, we will use longitudinal data derived from the Swedish population-registration system in order to get a picture of the childbearing dynamics of foreign-born women in Sweden, i.e., that of first-generation immigrants, during the last four decades of the last century. 
In our study, we display fertility levels of different immigrant groups in Sweden, stemming from different countries and regions of the world, and present changes over time in these levels. We also examine to what extent a migration affects the fertility of these women. In short, we focus on three different impacts on the childbearing behavior of foreign-born women and try to sort out the contributions from each of these factors on recorded behavior. The three effects can be summarized as:

- period effects in fertility,

- effects of country of origin, and

- effects of migration on child-bearing behavior.

period effects

Swedish fertility has shown strong fluctuations during the last four decades. Changes in the childbearing behavior of Swedish-born women have been presented by Andersson (1999) who displayed period trends in standardized first-, second-, third-, and fourth-birth rates of these women over the years since 1961. Rising fertility levels during the 1980s have recently been followed by sharp declines in the propensity to give birth during the $1990 \mathrm{~s}^{1}$. Andersson shows that this change in behavior pertains to Swedish women of all parities. An interesting feature behind the increase in secondbirth rates during the 1980 s is a shift towards shorter birth intervals after the arrival of a first child.

In this paper, we display as well period trends in parity-specific fertility of the two very broad groups of Nordic and Non-Nordic foreign-born women, in order to compare these trends with those of the Swedish-born population. This will give us information about whether women of other cultural and national backgrounds have been affected in a similar way by the drastic changes that have occurred in the general fertility climate in Sweden as have Swedish-born women. We might perhaps expect that the developments in childbearing of the Nordic group are rather similar to those of the Swedish-born, since these women come from countries with practically the

\footnotetext{
${ }^{1}$ When measured as Total Fertility Rate, fertility in Sweden has now decreased so much that it has reached the lowest value ever recorded for that country (the TFR was no higher than 1.5 in 1997-1999).
} 
same kind of culture and social systems like those of Sweden. Possible differences might be due to effects of the migration event or because women from these countries constitute a selective group with, for example, other socio-economic characteristics than those of the average Nordic population.

The group of women stemming from non-Nordic countries is of course an extremely heterogeneous group, comprising women from completely different types of countries, but we might anyway be able to see whether the birth rates of these women evolve over time in a manner similar to that of the Swedish population. We might here find a rather irregular pattern of fertility change since fairly high levels of immigration during the 1980s and the 1990s have resulted in strong compositional changes among these women over different countries of origin as well as over elapsed times since migration.

\section{effects of country of origin}

A comparison of fertility trends of various groups of women also gives the opportunity to display and compare levels in fertility between women of different countries of origin. In this case, we will expand our variable for country of birth of woman so that we present levels of standardized first-, second, third-, and fourth-birth rates for women stemming from 38 different countries or groups of countries. Each estimated level of childbearing is related to the corresponding level for the Swedish-born population.

Fertility differentials between women from different groups of countries may among other things be related to cultural differences in attitudes towards issues related to family and childbearing and to differences in existing patterns of childbearing in countries where the immigrants come from. When people migrate to a new country, they will bring important components of their original culture and behavior with them to their country of destination. Forste and Tienda (1996) give a brief summary of various hypotheses for fertility differentials between various ethnic groups in a country. As a complement to the hypothesis of a role of cultural factors as given above, they also refer to the idea that there is a (depressing) effect of minority-group status on fertility, and the hypothesis that variation in fertility simply is caused by 
selectivity, i.e., can be explained by the different social characteristics of different population groups.

Studies on fertility levels of immigrant women in the U.S. have among other things tried to determine the impact of fertility levels in their countries of origin on their fertility behavior in U.S.A. Abbasi-Shavazi and McDonald (2000) do the same for immigrants in Australia. In practically all studies of this kind, it is common to also examine whether one can find a process of assimilation in the fertility behavior of foreign-born women so that their fertility levels change from levels similar to those of their countries of origin to levels similar to that of the population of the country of destination. Kahn (1988) presents one such study and claims to find both an effect of assimilation and an effect of the country of origin on fertility levels of immigrant women in the U.S. Women from high-fertility countries tend to decrease their fertility levels with increasing exposure to their new country but the fertility level in the country of origin seems to continue to influence the childbearing behavior even after extended periods of time in the U.S. In the following section, we will refer more explicitly to such changes over time since a migration event on the fertility behavior of different groups of immigrants in a country.

\section{effects of migration}

In an examination of levels and trends in the fertility of immigrants, i.e., of the effects of country of origin and of period on childbearing propensities, it is also extremely important to consider the effect of time since the migration event on the fertility outcome. A lack of control for that factor may result in any conclusions about the fertility of immigrants. This was often the case in earlier studies on the relation between migration and fertility, then resulting in conflicting evidence about fertility levels of rural-urban migrants in the U.S. (see, f. ex., Zarate and Zarate, 1975). When dealing with international migration, this factor may turn out to be equally important as fertility levels of immigrants might change drastically when time since the migration event increases. In most studies of the fertility behavior of immigrants, this factor is also a main concern of the study itself, since changing levels of fertility in the country of destination tells something about these peoples experiences in their new country. The effects of migration on fertility may act in several ways though, depend- 
ing on the time horizon of interest. We may find a gradual effect that takes place over an extended period of time but we may also find temporary and short-term effects of the migration event on fertility. Stephen and Bean (1992) group these time-dependent effects into three different categories and label them as being evidence of:

- assimilation,

- adaptation, or

- disruption of the fertility behavior of immigrants.

Fertility levels of a group of immigrants may change gradually over time as the duration of their stay in their new country increases. In such a case, this might be taken as evidence of a process of assimilation of that group to the population of the receiving country, where increased exposure to the culture of that country increasingly will make the immigrant group resemble the native population. Seen in fertility figures, one would in this case expect a gradual convergence of fertility levels of the immigrant group to that of the native population. Gjerde and McCants (1995) give one description of such a process of assimilation in their study of fertility change among Norwegian immigrants in the U.S. in the second half of the $19^{\text {th }}$ century. Evidence of assimilation may be found also in other aspects of immigrants lives, such as patterns of residence (Park at al., 1925). The theory of assimilation was first formulated in Park and Burgess (1921) in an attempt to describe the phenomena of the American "melting-pot" experience, which Gordon (1964) refers to as a process of "AngloConformity". During recent decades, the idea of assimilation has come under increasing criticism as there has been a revival of interest on ethnicity and on the persistence of ethnical differences in various countries. Nevertheless, the possible process of assimilation should be studied over a fairly extended time horizon, preferably also including the experiences of children born to immigrants. Seen in this perspective, Massey (1985) and Hirshman (1983) found no evidence of decreasing levels of assimilation when studying real figures on different aspects of immigrants lives in the U.S. and Europe. However, Massey (1995) later admits that recent levels and patterns of migration to the U.S. may create completely new modes of behavior of contemporary immigrants. In a country like Sweden, where large-scale immigration 
still is quite a recent phenomena, it might be too early to judge whether various groups of immigrants tend to assimilate to the Swedish population or not.

Nevertheless, fertility levels of immigrants may change also if we focus on a shorter time horizon than that including one or two generations of immigrants. In this case, it might be more proper to think of the process as that of an adaptation of fertility behavior to that of the population of the receiving country. The idea is still that one might expect a convergence of fertility levels to those prevailing in the new country. This does however not necessarily imply a process of acculturation but can merely be seen as an adaptation to the situation in the new country, where other political, social-policy, labor-market, and gender systems may influence the fertility behavior in new manners. These influences might affect immigrants' childbearing in a similar way as they affect that of the native population, resulting in a convergence of fertility levels. In a study of fertility by time since migration for immigrants in Sweden, we prefer to label such a possible convergence of fertility levels as a process of adaptation, rather than that of assimilation, since we focus on changes in individual behavior relatively shortly after the migration event.

A proper investigation of patterns in fertility of immigrants also requires a consideration of the very short-term effects on childbearing that are connected with the migration event itself. In a study on childbearing behavior of regional migrants within Thailand, Goldstein and Goldstein (1981) found that the migration process interrupted childbearing so that the fertility of migrants was relatively low during the period preceding migration but higher than average immediately after migration. Hervitz (1985) tests the same hypothesis on internal migrants in Brazil and Kahn (1994) reports evidence of catching up effects in the childbearing of newly arrived immigrants in the U.S. Carlson (1985) found that immigrants to Australia seemed to experience a temporary disruption in their childbearing at the time of migration, but that later fertility behavior hardly was affected by the migration event. Such shortterm effects may be due to a sense of insecurity about future prospects while preparing for the migration; it might also stem from separation of spouses and to interruptions in economic activities at the time of migration. A pattern of spousal separation in international migration such as that described by Robles and Watkins (1993) for immigrants to the U.S. at the turn of the $20^{\text {th }}$ century is, for example, likely to result in catching up effects in the fertility of newly arrived women. However, there seems to 
be some confusion about whether observed elevated levels of fertility shortly after a migration really should be seen as evidence of a disruption in the childbearing process. $\mathrm{Ng}$ and Nault (1997) found elevated levels of fertility of very recent immigrants in Canada but rather took this finding as a rejection of the hypothesis of a disruption in childbearing around migration. They claimed that findings of "disruptions" often could be a result of inadequate data and methods, where cross-sectional census data hardly is the ideal source for an examination of dynamic processes such as childbearing.

Perhaps the common finding of elevated levels of fertility of newly arrived immigrants rather should be interpreted as a result of a situation where migration and family formation are interrelated with each other (Mulder and Wagner, 1993). If migration occurs in connection with family formation one would also expect elevated levels of childbearing immediately after - or even around - the time of migration. One specific case is marriage migration, where childbearing is presumed to start relatively shortly after the migration. Schoorl (1990) describes how the immigration of Moroccan and Turkish women to the Netherlands is strongly connected with marriage formation and Lievens (1997) makes similar observations for the same groups of immigrants in Belgium.

Stephan and Bean (1992) and Ford (1990) provide further examples of studies that deal with the fertility experiences of recent groups of immigrants in the U.S. They find evidence both of short-term "disruptive" effects on fertility in connection with migration and of the more gradual process of assimilation or adaptation to the fertility levels of the native American population. Ford (1990) shows that the short-term effects of migration generally are much stronger than the medium- or long-term effects of adaptation/assimilation. She concludes that it is always important to consider the effect of duration of time in the new country if one wants to be able to say anything about the fertility of various groups of immigrants. For a study of patterns in childbearing of foreign-born women in Sweden during the 1980s and the 1990s, it is of course extremely important to account for the fact that a large proportion of the foreign-born population at that time were relatively newly arrived in Sweden. In addition, a large fraction of these recent immigrants had spent extended periods of time waiting for asylum (as refugees) in Sweden. Such periods of uncertainty about the future might be related to patterns of disruptions in the childbearing of 
affected population groups. Consequently, many groups of immigrants in Sweden might be expected to experience relatively high levels of fertility, as they are catching up for reduced levels of childbearing at the time preceding their registration as immigrants in Sweden. If international migration otherwise often occurs in connection with family formation, we might equally expect elevated levels of fertility for other groups of newly arrived women in Sweden

As already mentioned, most studies on childbearing patterns of immigrants are based on census data which merely give information for various cross-sections in time. Ford (1990), Ng and Nault (1997), and others regret that this kind of data hardly is ideal for a proper analysis of fertility change when it is important to consider the dynamic nature of the childbearing process and its relation to migration. In order to grasp the various time-dependent aspects of such relations one ideally needs data with longitudinal information on both migration and childbearing. Carlson (1985) used a longitudinal data set from an Australian survey for his analysis but met criticism by Santow (1986) who argued that his set of data was not very appropriate for this kind of analysis either. While many demographic surveys provide potentially useful data, they are seldom directed specifically towards immigrants and thus contain too few observations for a more detailed analysis of childbearing patterns of immigrants. However, one recent exception to the common shortcomings in available data is given by Alders (2000) who studies immigrant fertility in the Netherlands with the help of information derived from the population registers of that country. He focuses on cohort fertility of various groups of immigrant women in the Netherlands and demonstrates, among other things, the existence of very elevated levels of childbearing of women from Turkey and Morocco immediately after their migration to the Netherlands.

In the following presentation, we will make use of a newly organized data set that has all the characteristics that we want for a proper study of the childbearing processes of immigrant women in Sweden. By using population-register data, we are provided with longitudinal information on sequences of births to all women living in Sweden, which allows for a study of parity-specific childbearing of various groups of women in that country. Consequently, we can study each step in the family-building process separately. In addition, our data set is based on such a huge number of observations that we can examine the specific behavior of several sub-groups of 
immigrants, stemming from all corners of the world, when it comes to levels and timing of their fertility.

\section{Data, study population, and method}

In Statistics Sweden, information about all recorded demographic events of women living in Sweden, such as immigration, emigration, and childbearing, is stored in a register called the Fertility Register. This register has so far contained longitudinal information for women born in Sweden in 1925 and later. At present, the same kind of data has also been gathered for women born abroad who have ever lived in Sweden in any of the years from 1968 onwards, which is the year when the Swedish populationregistration system became computerized and from when all individuals can be followed via a unique personal identity code. Information on foreign-born women identified in any of the censuses of 1960 and 1965 has also been added to the register.

All births occurring in Sweden have been linked to a mother. In addition, it has been possible to link children born abroad but at some time living in Sweden to their mother in Sweden, which results in more or less complete childbearing histories of the foreign-born women and allows for a distinction between births occurring before a migration to Sweden and births occurring after such a migration. Consequently, we are able to study each step of the family-building process separately and to relate each childbearing event to the event of a migration, when such an event is registered. We have no information on children who have not lived in Sweden, like those who might have died before their mother entered Sweden or were left behind in the country of origin. We restrict the problem of such omissions of children by only including in our study women who immigrated to Sweden at a maximum age of 35 years. This should guarantee that the vast majority of children to these women show up in Sweden and in our data, which then at least give a proper picture of the "social" parenthood of immigrant women.

A recorded date of immigration to Sweden is the date when an immigrant received a permanent residence permit. For the group of refugee migrants in the 1980s and the 1990s, there is often a considerable waiting time between the actual geographical move to Sweden and the time of approved and registered immigration. This 
time is generally spent in special refugee accommodations. Our data contain information on childbearing also of women who have emigrated from Sweden again - up to the date when an emigration is recorded. This means that our calculations of fertility measures are not subject to any problems of selectivity by virtue of survival/staying in Sweden. Such a selection can otherwise cause bias in fertility estimates if only the retrospective information from a remaining cross-sectional population can be used in the calculations (Sobolev and Andersson, 2001). In our calculations, we censor each woman at any first emigration from Sweden since we do not intend to examine the impact of cycle migration on the childbearing behavior in Sweden. In addition, we censor our observations at the occurrence of the death of a woman, at a multiple birth, at a fourth birth, ten years after the birth of a youngest child, or by the end of 1999, whichever comes first.

Immigration to Sweden increased during the second part of the 1980s and peaked during the first few years of the 1990s. At the same time, the composition of newly arrived immigrants changed from being dominated by labor migrants mainly from the neighboring Nordic countries, in particular from Finland, to an increasing fraction of refugee migrants from non-European countries and from the former Yugoslavia. At present, foreign-born people constitute a rather large fraction of the total population in Sweden. This becomes evident also in childbearing statistics, as around 17 percent of all children born in Sweden in the last few years of the 1990s were delivered by women born outside the country.

Table 1 shows the number of foreign-born women that are included in our study, by country of birth, and the number of births in Sweden from 1961 onwards to these women. Originally, we had information on 510,000 foreign-born women who had immigrated to Sweden at an age not higher than 35 years $^{2}$. After excluding women with lacking information on the exact date of the immigration to Sweden or on a proper country of origin, we are left with 446,000 immigrants. When appropriate, we have grouped the immigrant population into several country groups of origin ${ }^{3}$. Our

\footnotetext{
${ }^{2}$ Note that not all of these women still live in Sweden since some of them have again re-migrated out of the country.

${ }^{3}$ The label "Chinese", for example, stands for women stemming from mainland China, Taiwan, Hong Kong, and Singapore.
} 
study comprises women stemming from 38 different countries or groups of countries ${ }^{4}$. In addition, we use information on the childbearing histories of 2,973,000 Swedishborn women as a reference.

The most important groups of immigrants in Sweden according to their female population size are those stemming from Finland, Norway, Denmark, Poland, Germany, Yugoslavia, Turkey, Iran, Chile, and the group of “Arab" countries. Table 1 also displays the number of births in Sweden, by birth order, to women from the different groups. Note that the number of recorded second births sometimes exceeds the number of first births in Sweden. This holds, for example, for women stemming from Norway, Denmark, Germany, and Chile, and indicates that substantial fractions of women from these countries immigrated to Sweden as one-child mothers.

In our analyses, we use the same estimation techniques as those used by Andersson (1999) in his study of the childbearing behavior of the Swedish-born population. He estimated relative risks of first, second, third, and fourth births in each year of 1961-1997, standardized for the age of woman and for the age of any youngest child of hers. We refer to our estimation techniques as an improved form of indirect standardization (see Hoem, 1993, for this terminology). In practice, it amounts to the estimation of proportional-hazards models. Nowadays such models are a standard tool for analyses of time-dependent data. (See also Hoem, 1991, for a further description of our estimation techniques.)

We present separate relative risks of childbearing for each parity progression, based on the number of births and the appropriate population under risk of giving birth to a child of the actual order. We present separate analyses of first births for childless women in their 20s (16-28 years) and childless women in their 30s (31 years and older) since trends and patterns in fertility differ very much for younger and older nulliparous women (Andersson, 1999). For each birth type, we present relative risks of childbearing by calendar year, standardized for the other demographic variables that we can derive from our data. In addition, we present relative risks by country of birth, also standardized for the other variables in our data and, finally, relative risks of childbearing by duration in Sweden, again standardized for other variables available,

\footnotetext{
${ }^{4} 3,400$ immigrants stemming from a number of countries like South Africa, Israel, Albania, Cuba, Indonesia, Malaysia, and several small island states are not included in our study population since they deviate too much from their neighboring countries in order to be grouped together with them and also have too few observations in order to be represented in their own right.
} 
as well as a few interactions between our variables. The interaction between "country of birth" and "duration in Sweden", for example, gives us information about whether there are different patterns of "disruption" and "adaptation" in the fertility behavior of immigrants stemming from different types of countries. In our presentation, we interchangeably also refer to our relative risks as standardized birth rates that describe differences in childbearing intensities or in the propensity to give birth.

We use the following set of variables in our models:

- Calendar period, specified by single years from 1961 to 1999 in the analyses where we explicitly focus on period effects in childbearing, and by the aggregated periods of 1961-75, 1976-85, 1986-92, and 1993-99 in analyses where we merely use this variable as a control factor.

- Country of birth, specified as in Table 1, but sometimes with more aggregated groupings of countries.

- Duration in Sweden, or time since migration, with the levels "year 1, 2, 3, 4-5, 68, and 9+" for women who emigrated to Sweden at childbearing ages, i.e., at an age higher than 15. A special category of "childhood in Sweden" is used for women who immigrated before their $15^{\text {th }}$ birthday. When Swedish women are included in our analyses they are assigned to this level.

- Exact age of woman and, for higher birth orders, exact age of her youngest child. These two variables are merely used as control variables in order to standardize for the very strong age and timing effects that are evident in all childbearing dynamics.

In our calculations, we do not use any data on civil-status changes or on socioeconomic characteristics of the immigrant population. We do not expect that there is one specific relationship between such factors and the childbearing of women stemming from widely different countries. The examination of such relationships would then require a separate study, which we are not prepared to make at this stage. We want to focus on the purely demographic processes of childbearing by country of origin, calendar year, duration of time spent in Sweden, and age of woman and of any youngest child. An extension of our variable list would also require a restriction of our study to a much shorter calendar period than the one we can cover here. With this 
description of our available data in mind, we now proceed to the presentation of the results of our calculations.

\section{Period effects on childbearing of immigrants in Sweden}

In Figures 1-5, we present relative risks of childbearing, by calendar year, for each birth order and for three very broad categories of women: those born in Sweden, those born in other Nordic countries, and those who are born in non-Nordic countries. These diagrams give a very detailed picture of period changes in parity-specific childbearing over the years since 1961 and also says something about differences in childbearing intensities between women from our three groups of countries. Our calendar-year risks are calculated in exactly the same way as in Andersson (1999), i.e., they are standardized for age of woman and any youngest child but not for duration in Sweden. The analyses are made jointly for women of all nationalities with the relative risks of the interaction factor of "calendar year" and "country-group of birth" presented in our diagrams.

Figure 1 contains relative risks of entry into motherhood for childless women aged 16-28 years. For Swedish-born women at those ages, first-birth rates decrease over time, except that the decline is interrupted by increasing birth intensities during the Swedish baby-boom years in the 1980s. First-birth intensities of young women born in the other Nordic countries show very similar trends but are at a substantially higher level than those of the Swedish-born population. This difference in level tends to narrow over time. Women born in non-Nordic countries exhibit even higher levels of first-birth rates, except in the 1960s. There seems to be a great degree of covariation with the fertility trends of the Swedish-born population for this group as well, even though the changes over time are slightly more irregular for these women. A special feature is the moderate level of first-birth fertility during the 1960s when this

group mainly consisted of women stemming from European countries.

Figure 2 similarly shows the standardized first-birth rates for childless women at ages 31-45 years. At these higher ages, both the trends over time and the levels of birth intensities seem to be pretty similar for Swedish-born and other Nordic women, with fairly stable levels during the 1960s and the 1970s, increasing birth intensities 
during the 1980s, and stabilizing intensities during the 1990s. The increase in the 1980s reflects the tendency of a general postponement of entry into motherhood in Sweden. The group of non-Nordic women also seems to be affected by similar period effects, though their first-birth rates are found at higher levels than those of the Nordic population.

When we look at standardized second-birth rates by calendar year and countrygroup of birth (Figure 3), we again find that changes over time are very similar for women born in Sweden and women born in other Nordic countries. However, in this case, the propensity to give birth is the highest among Swedish-born women, probably reflecting a stronger impact of the Swedish two-child norm on the childbearing behavior of this group. The most drastic change in second-birth rates occurred during the 1980s when they increased at a very fast pace both for Swedish- and foreign-born Nordic women. An interesting observation from Figure 3 is otherwise the apparent lack of any major period change in the second-birth rates of the non-Nordic population.

Finally, in Figure 4, we present standardized third-birth rates by period and country-group of birth and, in Figure 5, similar fourth-birth rates. At these higher birth orders, we might perhaps have expected more pronounced differences in the fertility behavior of women from different country-groups of origin but instead we find again surprisingly similar patterns of childbearing for our three groups of women. For thirdbirth rates, there is a striking similarity both in levels of birth intensities and in how they evolve over time. One exception is that the third-birth rates of non-Nordic women decreased at a much slower pace in the 1990s than the rates of women born in the Nordic countries. For fourth-birth rates, there is also a striking similarity in the period effects for women from the different country groups, with decreasing levels up to the mid 1970s, then increasing levels until the end of the 1980s, and again decreasing levels during the 1990s. In general, the trends in fourth-birth rates are very similar to those in third-birth rates. However, in this case the curve for non-Nordic women consistently stands at a higher level than the curve for Nordic women from the early 1970s onwards. We also notice that the patterns by single calendar years are very irregular for both groups of immigrant women. This is mainly due to smaller number of observations in the foreign-born population, which becomes especially evident in a presentation of rates for a rare birth order like that of the fourth child. 
The presentation given in this section has provided us with a detailed picture of period changes in the childbearing propensities of foreign-born women in Sweden since the early 1960s. When we were able to study such processes separately by birth order we found that changes over time in most cases were surprisingly similar for immigrant and native-born women. We could also track the existence of various differences in levels in parity-specific childbearing between women stemming from the different country-groups of origin that we used. We now turn to a more detailed description of such differences in levels of childbearing, where we disaggregate the foreign-born population into much finer country-of-origin categories.

\section{Effects of country of origin on fertility of immigrant women in Sweden}

In Table 2 we present relative risks of parity-specific childbearing by country of origin. These risks are standardized for the effect of calendar period, age of woman and of any youngest child, but not for time since immigration. The risks are given relative to corresponding risks of Swedish-born women and are presented for 38 different countries or groups of countries.

A first overview of the various relative risks of childbearing reveals some very general patterns in birth intensities by country of origin. First, practically all groups of immigrant childless women seem to have a higher propensity to become a mother than do childless Swedish women at corresponding ages and calendar-year periods. In contrast, at the progression from a first to a second child, the reverse holds. Most country groups have a significantly lower standardized second-birth rate than that of Swedish one-child mothers. At higher parities, we again find that most immigrant groups have higher childbearing propensities than the Swedish-born population.

A closer examination of the risk patterns in Table 2 gives much more detail to this picture. One interesting group of women is given by those stemming from the other Nordic countries. Since they come from societies which in practically all aspects are very close to the Swedish one, we would perhaps expect a childbearing behavior that is very close to that of the Swedish population. Instead, we find that their childbearing intensities at most parities are substantially higher than the corresponding intensity of the Swedish-born. A much more similar (to the Swedish) pattern of child- 
bearing is instead given by women stemming from other Western European countries. It is here interesting to note that women coming from notoriously low-fertility Germany do not exhibit a lower propensity for childbearing at all once they live in Sweden, but rather have levels slightly higher than those of the Swedish-born population.

A group of women with a fairly low fertility in Sweden is instead given by immigrants from most Eastern European countries. While they have first-birth intensities at or above the levels of the Swedish population, they demonstrate very low levels of childbearing after the arrival of a first child. The low propensity for secondchildbearing is also shared by women stemming from China, possibly reflecting the prevailing one-child policy of that country. Another group which at most parities has a low fertility level is women stemming from Korea, but this is a very special case; most of these women are not "normal" immigrants but arrived in Sweden at very young ages as adoptees in Swedish families.

A distinct group of women with an elevated level of childbearing at all parities is otherwise given by those stemming from various "Moslem" countries. Women from Turkey exhibit high fertility levels as do women from the Arab-speaking countries in the Middle East and North Africa, and women from countries like Pakistan. The most pronounced high-fertility group in Sweden seems to be those stemming from Somalia. It is interesting to note that their childbearing propensities widely exceed the corresponding propensities for women stemming from other parts of sub-Saharan Africa. However, a clear and interesting exception to the rule of elevated fertility levels of women from Moslem countries is given by the Iranian immigrant group in Sweden who instead has a distinctly low-fertility behavior, not too different from that of women stemming from Eastern Europe. In addition, we seem to find a relatively highfertile group in the Vietnamese population in Sweden. Women from Latin America generally exhibit fertility levels that are fairly close to those of the Swedish-born population (with the exception of strongly elevated first-birth rates of young Chileans). Finally, women from "New World" countries like USA, Australia, and Canada are distinguished by low first-birth fertility in Sweden but relatively high levels of parity progression once they have started childbearing.

An important general conclusion from the huge number of figures presented in Table 2 is that childbearing propensities in many cases are higher for immigrant 
women than for the native-born population in Sweden. This holds at least for firstbirth rates and most often also for the intensities of births of orders above 2 . In order to better understand to what extent these elevated risks of childbearing really reflects a high-fertility behavior of various ethnic and national groups in Sweden, we need to study patterns in childbearing by duration of time spent in Sweden. Such an investigation can tell us more about to what extent the elevated fertility rates are due to a permanent behavior of minority groups in Sweden or to what extent they reflect temporary fluctuations in the behavior immediately following a migration.

\section{Effects of migration on childbearing of immigrants}

Our Table 3 contains relative risks of childbearing by birth order and duration in Sweden. These risks are standardized for calendar period, country of birth (as in Tables 1-2), and age of woman and of any youngest child. Women who arrived in Sweden before age 15 belongs to a separate category called "childhood in Sweden" since they are not directly affected in their childbearing by a migration event during their reproductive ages. Swedish-born women are also assigned to this category, which serves as a reference group.

The table reveals a very clear and distinct pattern of childbearing propensities by time spent in Sweden. The most important finding is that first-birth rates of immigrants appear to be elevated by some 100 percent during the first two years in Sweden, but after a period of say five years they do not deviate much at all from the fertility level of women who spent at least part of their childhood in Sweden. Secondbirth intensities are relatively unaffected by time in Sweden; they are more or less the same for women who are newly arrived in the country, for those who have lived there for an extended period of time, and for those who lived there already before their $15^{\text {th }}$ birth day, when we control for the effect of our other demographic variables. However, the propensity for higher-order childbearing again seems to be affected by the time since a registered migration to Sweden. Third- and fourth-birth rates are around 50 percent higher for newly arrived migrants than for immigrants who have lived there for more than five years and for those who lived in Sweden already at age 15. An interaction between the variables describing time since migration and the 
length of the preceding birth interval reveals that this latter fertility-stimulating effect of a recent migration event works at both very short and very long birth intervals (not shown here). Evidently, an international migration speeds up the continued childbearing of two- and three-child mothers at short birth intervals and also stimulates a renewed propensity for third- and fourth-birth childbearing at the longer intervals.

The most interesting findings from our Table 3 were the strongly elevated first-birth risks and moderately elevated third- and fourth-birth risks very shortly after a migration to Sweden. In particular, it is noteworthy that these birth risks are elevated already in the first twelve months after such a migration, which means that many of the children born there were actually conceived before the registered immigration in Sweden. This hardly gives any support for the notion of "disruptions" in childbearing in connection with international migration. In addition, our finding of a complete lack of elevated fertility levels for immigrants who have lived in Sweden for 6-8 years or more suggests that reports of elevated fertility of various groups of immigrants based on aggregate data, for example, mainly are due to the fact that a lot of childbearing occurs to newly arrived immigrants.

With these general patterns in the impact of duration in Sweden on childbearing intensities of immigrants, one of course wonders to what extent these patterns also hold for subgroups of immigrants from different types of countries. In addition, we wonder whether the differences that we observed in levels of childbearing by country of origin (Table 2) also hold when we account for the effect of time since migration. The latter question can simply be answered by re-estimating the relative risks of Table 2 with duration in Sweden included as another control factor. Such estimation results in substantial reductions or even disappearances of the super-risks of childbearing of immigrants at the various birth orders (not shown here). However, since we want to compare childbearing propensities of immigrants by both duration in Sweden and by country-group of origin with those of the Swedish-born population, it will be more lucid to present calculated relative risks for the interaction factor describing the combined effect of the two variables. This also makes sense since the variable for duration in Sweden has no real meaning for Swedish-born women.

In order to get an appropriate overview of our interaction results, we first make some aggregations of our data, both concerning the categories for duration in Sweden and for country of origin. This allows us to digest all the information we produce and 
also gives a sufficient number of observations at all possible combinations of factor levels. For duration in Sweden, we now switch to three categories: "childhood in Sweden", "first three years in Sweden", and "years 6 and above". We use the following country-groups of immigrants: other Nordic countries, Western Europe, Eastern Europe, New-World countries (U.S.A., Canada, Australia, New Zealand), "Moslem" countries in North Africa and South West Asia (excluding Iran), Iran, South Asia (including India, Indochina, Thailand, the Philippines), Latin America, and sub-Saharan Africa. Immigrants from the European Mediterranean countries and from East Asia are not included in this step of the analysis. All calculated risks are given relative to a baseline group of Swedish-born women.

The relative risks of parity-specific childbearing by country group of origin and duration in Sweden are presented in Table 4. (As usual, these risks are standardized for calendar period, age of woman, and age of any youngest child.) Tables 4a and $4 \mathrm{~b}$ display the results concerning first births of younger and older childless women, respectively. They demonstrate very clearly that the general pattern of elevated levels of first-birth fertility immediately after a migration to Sweden actually holds for women coming from all corners of the world. The magnitude of this effect differs but we find it for country groups where most refugee immigrants stem from as well as for those neighboring countries that mainly have supplied Sweden with labor migrants. Particularly high levels of first-birth rates are recorded for newly arrived immigrants from Turkey, North Africa, the Middle East, and countries alike. If we instead focus on the immigrant sub-populations who arrived to Sweden during childhood or who have lived in Sweden for a period of at least five years, we can rather see that very few of them have a higher propensity for first-birth childbearing than the Swedish-born population has. In these cases, with the notable exception of young women stemming from the various Moslem countries, we often find that immigrant women instead exhibit a slightly lower propensity to become a mother than native-born women does.

As expected, second-birth risks by country-group of origin are not affected in a systematic way by the time spent in Sweden (Table 4c) and for other immigrant populations than those stemming from the various Moslem countries such birth rates

\footnotetext{
${ }^{5}$ In this step of our analysis, we simply leave out the observations that pertain to the intermediate category of a duration of 4-5 years in Sweden.
} 
are typically lower than that of the Swedish-born population. Again, we find that the behavior of Iranian women contrasts sharply from that of women stemming from other Moslem countries; Iranians demonstrate a particularly low propensity to have a second child regardless of their time spent in Sweden. Our previous findings of elevated third- and fourth-birth risks immediately after an international migration turn out to be common, but not at all universal, among our various country groups of immigrants (Tables $4 \mathrm{~d}$ and $4 \mathrm{e}$ ). Such effects are important for women stemming from Nordic, Western European, Moslem, South Asian, and sub-Saharan countries. Immigrants from Moslem countries and from New-World countries have levels of third- and fourth-birth risks that are higher than for the Swedes regardless of the time since migration to Sweden. Women from sub-Saharan Africa exhibit elevated levels of higher-order childbearing also after an extended period of time in Sweden while Iranian women again stand out by having very low levels of third- and fourth-birth fertility relative to that of the Swedish-born population.

\section{Summary of results and concluding remarks}

In this study, we have used longitudinal data on childbearing derived from the Swedish population registers in order to examine period patterns, effects of country of origin, and the impact of migration on the childbearing behavior of immigrant women in Sweden. We began with a presentation of period trends in childbearing of women from a limited number of broad country groups, suggesting that immigrant women after all might have been affected in a way that is very similar to that of the Swedishborn population by various changes in the general climate of childbearing in Sweden over the last four decades. For example, decreasing levels of parity-specific fertility during the 1990s seem to be due to decreasing childbearing intensities among Swedish- and foreign-born women alike.

In our examination of childbearing levels by country of origin, we found that most immigrant groups had elevated levels of first-birth rates in Sweden and that many groups also display higher levels of third- and fourth-birth rates than the Swedish population does. For second-birth rates it is the Swedish-born population that stands out with an elevated propensity for continued childbearing. Evidently, the 
strong two-child norm in Swedish society has a more profound impact on the behavior of the native group than on the behavior of foreign-born people.

A closer examination reveals that many of the observed differences in levels of parity-specific childbearing between the Swedish- and the foreign-born populations are due to elevated birth risks of most immigrants shortly after their migration to Sweden. This is particularly evident in first-birth rates. Practically all groups of immigrant childless women display elevated propensities of entry into motherhood during their first few years in Sweden. We also found elevated levels of third- and fourth-birth risks for many groups of newly arrived immigrants in Sweden. In contrast, for immigrants who have lived in Sweden for at least five years and for immigrants who arrived there before they turned 15, we seldom find any evidence of high-fertility behavior. Immigrants stemming from various Moslem countries are an exception to this observation.

Our findings of elevated levels of childbearing immediately after a migration to Sweden hardly give any support for the notion of "disruptions" in childbearing in connection with international and other long-distance migration. Instead, they seem to suggest that migration and family formation in many cases are interrelated events. In the case of marriage migration, for example, we would expect elevated levels of firstbirth rates shortly after migration, as we observe here. For higher birth orders, we also find that a migration seems to trigger rather than to disrupt the process of childbearing. In contrast, our finding that levels of fertility of immigrants who have lived in Sweden for a period of at least five years in most cases are very similar to the levels of the Swedish-born instead gives support to the idea of rather rapid adaptation of the childbearing behavior to that prevailing in the country of destination.

To wind up, we stress again that it is very important to consider the time evolved since immigration if one wants to get a fair picture of the fertility behavior of various groups of immigrants. By using longitudinal data covering a large number of foreign-born women in Sweden, we have been able to get a much more accurate picture of such processes than those provided by earlier studies. In future research, it would be very interesting to also examine how the observed patterns in childbearing are related to socio-economic characteristics of the various immigrant sub-populations and how they are interrelated with the broader process of their economic integration into Swedish society. 


\section{Acknowledgements}

I want to express my deep gratitude to Britta Hoem at Statistics Sweden for organizing and cleaning the raw data that I have used in my analyses. I'm also grateful for inspiring advice from Calvin Goldscheider, for comments from Jan Hoem and for comments received at a seminar at the Stockholm University Demography Unit.

\section{References}

Abbasi-Shavazi, M. J., and McDonald, P., 2000. Fertility and multiculturalism: Immigrant fertility in Australia, 1977-1991. International Migration Review 34: $215-242$.

Alders, M., 2000. Cohort fertility of migrant women in the Netherlands. Paper at the BSPS-NVD-URU Conference, 31 August - 1 September 2000, Utrecht, The Netherlands.

Andersson, G., 1999. Childbearing trends in Sweden 1961-1997. European Journal of Population 15: 1-24.

Bean, F., and Swicegood, C., 1985. Mexican American Fertility Patterns. University of Texas Press, Texas.

Bean, F., and Tienda, M., 1987. The Hispanic Population of the United States. Russell Sage Foundation, New York.

Carlson, E., 1985. The impact of international migration upon the timing of marriage and childbearing. Demography 22: 61-72.

Coleman, D., and Salt, J., 1996. Ethnicity in the 1991 Census. HMSO, London.

Ford, K., 1990. Duration of residence in the United States and the fertility of US immigrants. International Migration Review 24: 34-68.

Forste, R., and Tienda, M., 1996. What's behind racial and ethnic fertility differentials? Population and Development Review, a Supplement to Vol. 22: 109133. 
Gjerde, J., and McCants, A., 1995. Fertility, marriage, and culture: Demographic processes among Norwegian immigrants to the rural Middle West. The Journal of Economic History 55: 860-888.

Goldscheider, C., and Uhlenberg, P., 1968. Minority group status and fertility. The American Journal of Sociology 74: 361-372.

Goldstein, S., and Goldstein, A., 1981. The impact of migration on fertility: an 'own children' analysis for Thailand. Population Studies 35: 265-284.

Gordon, M., 1964. Assimilation in American Life. Oxford University Press, New York.

Hervitz, H., 1985. Selectivity, adaptation, or disruption? A comparison of alternative hypotheses on the effects of migration on fertility: The case of Brazil. International Migration Review 19: 293-317.

Hirschman, C., 1983. America's melting pot reconsidered. Annual Review of Sociology 9: 397-423.

Hoem, B., and Hoem, J., 1996. Sweden's family policies and roller-coaster fertility. Jinko Mondai Kenkyu (Journal of Population Problems) 52: 1-22.

Hoem, J.M., 1991. La standardisation indirecte améliorée et son application à la divortialité en Suède (1971-1989). Population 46: 1551-1568.

Hoem, J.M., 1993. Classical demographic methods of analysis and modern eventhistory techniques. IUSSP: 22nd International Population Conference, Montreal, Canada, Volume 3: 281-291.

Kahn, J., 1988. Immigrant selectivity and fertility adaptation in the United States. Social Forces 67: 108-128.

Kahn, J., 1994. Immigrant and native fertility during the 1980s: Adaptation and expectations for the future. International Migration Review 28: 501-519.

Landale, N., and Hauan, S., 1996. Migration and premarital childbearing among Puerto Rican women. Demography 33: 429-442.

Lievens, J., 1997. The third wave of immigration from Turkey and Morocco: Determinants and characteristics. IPD-Working Paper 1997-2, Universiteit Gent, Belgium.

Massey, D., 1985. Ethnic residential segregation: a theoretical synthesis and empirical review. Sociology and Social Research 69: 315-350. 
Massey, D., 1995. The new immigration and ethnicity in the United States. Population and Development Review 21: 631-652.

Mulder, C., and Wagner, M., 1993. Migration and marriage in the life course: a method for studying synchronized events. European Journal of Population 9: $55-76$.

Ng, E., and Nault, F., 1997. Fertility among recent immigrant women to Canada, 1991: An examination of the disruption hypothesis. International Migration 35: 559-580.

Park, R., and Burgess, E., 1921. Introduction to the Science of Sociology. University of Chicago Press.

Park, R., Burgess, E., and McKenzie, R., 1925. The City. University of Chicago Press.

Robles, A., and Watkins, S., 1993. Immigration and family separation in the U.S. at the turn of the twentieth century. Journal of Family History 18: 191-211.

Santow, G., 1986. A comment on Elwood Carlson's "The impact of international migration upon the timing of marriage and childbearing”. Demography 23: 467-468.

SCB, 1996. Befolkningsstatistik del 4, 1995. Statistics Sweden, Stockholm.

Schoorl, J., 1990. Fertility adaptation of Turkish and Moroccan women in The Netherlands. International Migration 28: 477-495.

Sean-Shong, H., and Saenz, R., 1997. Fertility of Chinese immigrants in the U.S.: testing a fertility emancipation hypothesis. Journal of Marriage and the Family 59: 50-61.

Sobolev. B., and Andersson, G., 2001. How big is the problem of selective migration in retrospective studies of fertility? Work in progress, Max Planck Institute for Demographic Research, Rostock, Germany.

Stephan, G., and Bean, F., 1992. Assimilation, disruption, and the fertility of Mexican American women in the United States. International Migration Review 26: 6788.

Zarate, A., and Zarate, A., 1975. On the reconciliation of research findings of migrantnonmigrant fertility differentials in urban areas. International Migration Review 9: 115-156. 
Table 1: Number of foreign-born women under study and births to these women occurring in Sweden in 1961-1999

\begin{tabular}{|c|c|c|c|c|c|}
\hline Country of origin & women & 1st births & 2nd births & 3rd births & 4th births \\
\hline Finland & 126,576 & 56,314 & 54,454 & 23,909 & 8,140 \\
\hline Norway & 25,220 & 8,140 & 9,208 & 4,168 & 1,360 \\
\hline Denmark & 20,439 & 6,112 & 7,262 & 3,668 & 1,404 \\
\hline Iceland & 4,314 & 716 & 804 & 466 & 148 \\
\hline Germany & 16,698 & 6,075 & 7,907 & 3,351 & 1,047 \\
\hline BeNeLux & 2,447 & 846 & 810 & 328 & 117 \\
\hline Austria-Switzerland & 3,270 & 1,314 & 1,343 & 544 & 158 \\
\hline British Islands & 6,657 & 2,246 & 1,867 & 742 & 190 \\
\hline France & 2,406 & 799 & 615 & 229 & 68 \\
\hline Italy-Spain-Portugal & 5,491 & 2,376 & 1,969 & 687 & 211 \\
\hline Estonia-Latvia & 1,985 & 604 & 737 & 284 & 78 \\
\hline Soviet states & 5,758 & 1,508 & 1,312 & 390 & 106 \\
\hline Poland & 19,685 & 8,642 & 6,628 & 1,763 & 384 \\
\hline Czech-Slovakia & 3,502 & 1,437 & 1,315 & 425 & 116 \\
\hline Hungary & 5,581 & 2,306 & 2,067 & 689 & 183 \\
\hline Romania-Bulgaria & 5,251 & 1,361 & 1,013 & 228 & 56 \\
\hline Yugoslavia & 41,709 & 13,126 & 12,996 & 4,696 & 1,362 \\
\hline Greece & 6,376 & 3,231 & 2,972 & 975 & 149 \\
\hline Turkey & 12,239 & 6,380 & 5,571 & 3,601 & 2,039 \\
\hline Arab countries & 27,781 & 11,314 & 9,529 & 5,947 & 2,974 \\
\hline Iran & 17,620 & 4,466 & 3,580 & 1,061 & 240 \\
\hline Pakist-Bangl-Afgh & 3,159 & 1,299 & 1,031 & 547 & 219 \\
\hline India - Sri Lanka & 7,891 & 2,105 & 1,417 & 486 & 122 \\
\hline Thailand & 5,950 & 1,901 & 1,383 & 477 & 133 \\
\hline Vietnam/Indochina & 4,249 & 1,558 & 1,372 & 754 & 349 \\
\hline Philippines & 3,242 & 1,383 & 980 & 360 & 106 \\
\hline Chinese & 3,569 & 1,232 & 813 & 243 & 43 \\
\hline Korea & 5,157 & 1,315 & 758 & 189 & 29 \\
\hline Japan & 1,806 & 526 & 357 & 96 & 16 \\
\hline Australia-NZ-Canada & 2,751 & 736 & 532 & 185 & 54 \\
\hline US & 7,254 & 1,944 & 1,469 & 542 & 164 \\
\hline Chile & 11,515 & 3,068 & 3,238 & 1,766 & 604 \\
\hline Argentina-Uruguay & 2,603 & 748 & 741 & 325 & 93 \\
\hline Brazil & 1,866 & 604 & 410 & 135 & 30 \\
\hline Other Hispanic Am. & 7,765 & 1,988 & 1,699 & 669 & 199 \\
\hline Ethiopia & 6,041 & 2,044 & 1,677 & 896 & 439 \\
\hline Somalia & 4,429 & 1,299 & 1,312 & 997 & 621 \\
\hline Other Subsahara & 5,627 & 1,594 & 1,407 & 767 & 317 \\
\hline Total & 445,879 & 164,657 & 154,555 & 67,585 & 24,068 \\
\hline
\end{tabular}


Table 2: Relative risk" of childbearing by birth order and country of origin, standardized for calendar period, age of woman, and age of any youngest child.

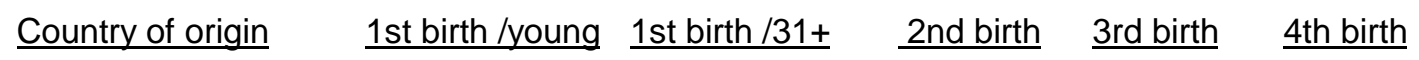

Sweden

Finland

Norway

Denmark

Iceland

\section{1}

1.43

1.77

1.58

1.44

Germany

BeNeLux

Austria-Switzerland

British Islands

France

Italy-Spain-Portugal

Estonia-Latvia

Soviet states

Poland

Czech-Slovakia

Hungary

Romania-Bulgaria

Yugoslavia

Greece

Turkey

Arab countries

Iran

Pakist-Bangl-Afgh

India - Sri Lanka

Thailand

Vietnam/Indochina

Philippines

Chinese

Korea

Japan

Australia-NZ-Canada

US

Chile

Argentina-Uruguay

Brazil

Other Hispanic Am.

Ethiopia

Somalia

Other Subsahara
1.17

1.00

1.01

0.96

0.96

1.37

0.91

1.55

1.53

0.99

1.22

1.30

2.24

2.17

3.67

3.84

1.23

3.06

1.43

1.67

1.66

2.32

1.48

0.68

0.99

0.84

0.64

1.71

1.29

1.24

1.29

1.20
3.80
1.91

0.96

1.09

1.05

1.07

1.12

1.31

1.19

1.19

1.26

1.35

1.07

1.29

1.31

1.18

1.14

1.02

1.08

0.98

1.37

1.97

1.34

1.52

1.74

1.06

1.10

1.60

1.30

0.91

1.13

1.01

1.04

1.32

1.39

1.28

1.51

1.07

1.52

0.92

1
$\mathbf{0 . 8 7}$
$\mathbf{1 . 0 2}$
$\mathbf{1 . 0 6}$
0.94

1

1

0.98
1.29

1.02

1.12

1.13

1.19

1.24

1.27

1.46

1.40

0.95

1.15

1.15

$1.45 \quad 1.78$

1.13

1.06

1.03

0.87

1.30

1.30

0.81

1.30

1.46

1.40

0.89

1.00

0.57

1.03

1.25

0.75

0.86

1.06

0.67

0.77

1.11

0.52

0.72

0.95

$\mathbf{0 . 4 9} 1.02$

0.93

0.74

1.05

1.21

0.72

0.51

1.21

1.87

2.16

1.46

2.55

2.51

0.59

0.57

0.72

1.10

1.84

1.92

\subsection{8}

1.21

1.30

0.61

1.10

1.33

1.21

2.06

2.37

0.64

1.23

1.50

$*$ risks are given with bold face when significantly $<>1$ at a probability level of $5 \%$ 
Table 3: Relative risk of childbearing by birth order and duration in Sweden, standardized for calendar period, country of origin, age of woman, and age of any youngest child.

\begin{tabular}{|c|c|c|c|c|c|}
\hline time after migration & 1st birth /young & 1st birth $/ 31+$ & 2nd birth & 3rd birth & 4th birth \\
\hline childhood in Sweden & 1 & 1 & 1 & 1 & 1 \\
\hline year 1 & 1.93 & 2.31 & 1.10 & 1.34 & 1.46 \\
\hline year 2 & 1.91 & 2.34 & 1.23 & 1.53 & 1.57 \\
\hline year 3 & 1.41 & 1.77 & 1.11 & 1.42 & 1.49 \\
\hline years 4-5 & 1.15 & 1.53 & 0.98 & 1.30 & 1.38 \\
\hline years $6-8$ & 0.96 & 1.24 & 0.98 & 1.11 & 1.18 \\
\hline years $9+$ & 0.83 & 1.07 & 0.93 & 0.98 & 1.03 \\
\hline
\end{tabular}


Table 4a: Relative risk of entry into parenthood for childless women aged 16-28, by country-group of origin and by duration in Sweden, standardized for calendar period and age of woman.

\section{childhood in Sweden first 3 years after 5 years}

$\begin{array}{lccc}\text { Sweden } & 1 & - & - \\ \text { Nordic } & 1.41 & 1.76 & 1.08 \\ \text { West Europe } & 0.94 & 1.28 & 0.96 \\ \text { East Europe } & 0.84 & 1.98 & 0.98 \\ \text { "New World" } & 0.64 & 0.72 & 0.61 \\ \text { Moslem countries } & 1.86 & 6.16 & 1.90 \\ \text { Iran } & 0.41 & 1.87 & 0.77 \\ \text { South Asia } & 0.83 & 2.82 & 1.55 \\ \text { Latin America } & 1.17 & 2.08 & 1.34 \\ \text { Subsahara } & 0.79 & 2.76 & 1.27\end{array}$

Table 4b: Relative risk of entry into parenthood for childless women aged 31-45, by country-group of origin and by duration in Sweden, standardized for calendar period and age of woman.

childhood in Sweden first 3 years after 5 years

$\begin{array}{lccc}\text { Sweden } & 1 & - & - \\ \text { Nordic } & 0.79 & 1.53 & 0.93 \\ \text { West Europe } & 0.94 & 1.81 & 0.97 \\ \text { East Europe } & 0.91 & 1.91 & 1.01 \\ \text { "New World" } & 1.02 & 1.42 & 0.77 \\ \text { Moslem countries } & 0.90 & 3.00 & 0.99 \\ \text { Iran } & 0.88 & 2.02 & 1.02 \\ \text { South Asia } & 0.79 & 1.98 & 0.90 \\ \text { Latin America } & 0.77 & 1.90 & 1.11 \\ \text { Subsahara } & 0.85 & 1.51 & 0.89\end{array}$


Table 4c: Relative risk of second birth of one-child mother, by country-group of origin and by duration in Sweden, standardized for calendar period, age of woman, and age of first child.

\section{childhood in Sweden first 3 years after 5 years}

$\begin{array}{lccc}\text { Sweden } & 1 & - & - \\ \text { Nordic } & 0.91 & 1.09 & 0.82 \\ \text { West Europe } & 1.00 & 1.08 & 0.96 \\ \text { East Europe } & 0.85 & 0.59 & 0.59 \\ \text { "New World" } & 0.99 & 0.99 & 1.13 \\ \text { Moslem countries } & 1.14 & 1.65 & 1.24 \\ \text { Iran } & 0.62 & 0.55 & 0.67 \\ \text { South Asia } & 0.83 & 0.90 & 0.80 \\ \text { Latin America } & 0.69 & 0.84 & 0.81 \\ \text { Subsahara } & 0.73 & 1.47 & 1.11\end{array}$

Table 4d: Relative risk of third birth of two-child mother, by country-group of origin and by duration in Sweden, standardized for calendar period, age of woman, and age of second child.

\section{childhood in Sweden first 3 years after 5 years}

Sweden
Nordic
West Europe
East Europe
"New World"
Moslem countries
Iran
South Asia
Latin America
Subsahara

1
1.00
1.07
0.90
1.24
1.48
0.93
1.18
0.96
0.99


Table 4e: Relative risk of fourth birth of three-child mother, by country-group of origin and by duration in Sweden, standardized for calendar period, age of woman, and age of third child.

childhood in Sweden first 3 years after 5 years

$\begin{array}{lccc}\text { Sweden } & 1 & - & - \\ \text { Nordic } & 1.08 & 1.54 & 1.10 \\ \text { West Europe } & 1.19 & 1.51 & 1.14 \\ \text { East Europe } & 0.89 & 1.19 & 1.07 \\ \text { "New World" } & 1.76 & 1.34 & 1.81 \\ \text { Moslem countries } & 1.53 & 3.16 & 2.15 \\ \text { Iran } & - & 0.70 & 0.69 \\ \text { South Asia } & 1.29 & 2.53 & 1.46 \\ \text { Latin America } & 1.16 & 1.03 & 1.30 \\ \text { Subsahara } & 1.10 & 3.62 & 2.82\end{array}$


Figure 1: Standardized annual index of first-birth rates. Childless women aged 16-28, 1961-1999, by country-group of origin.

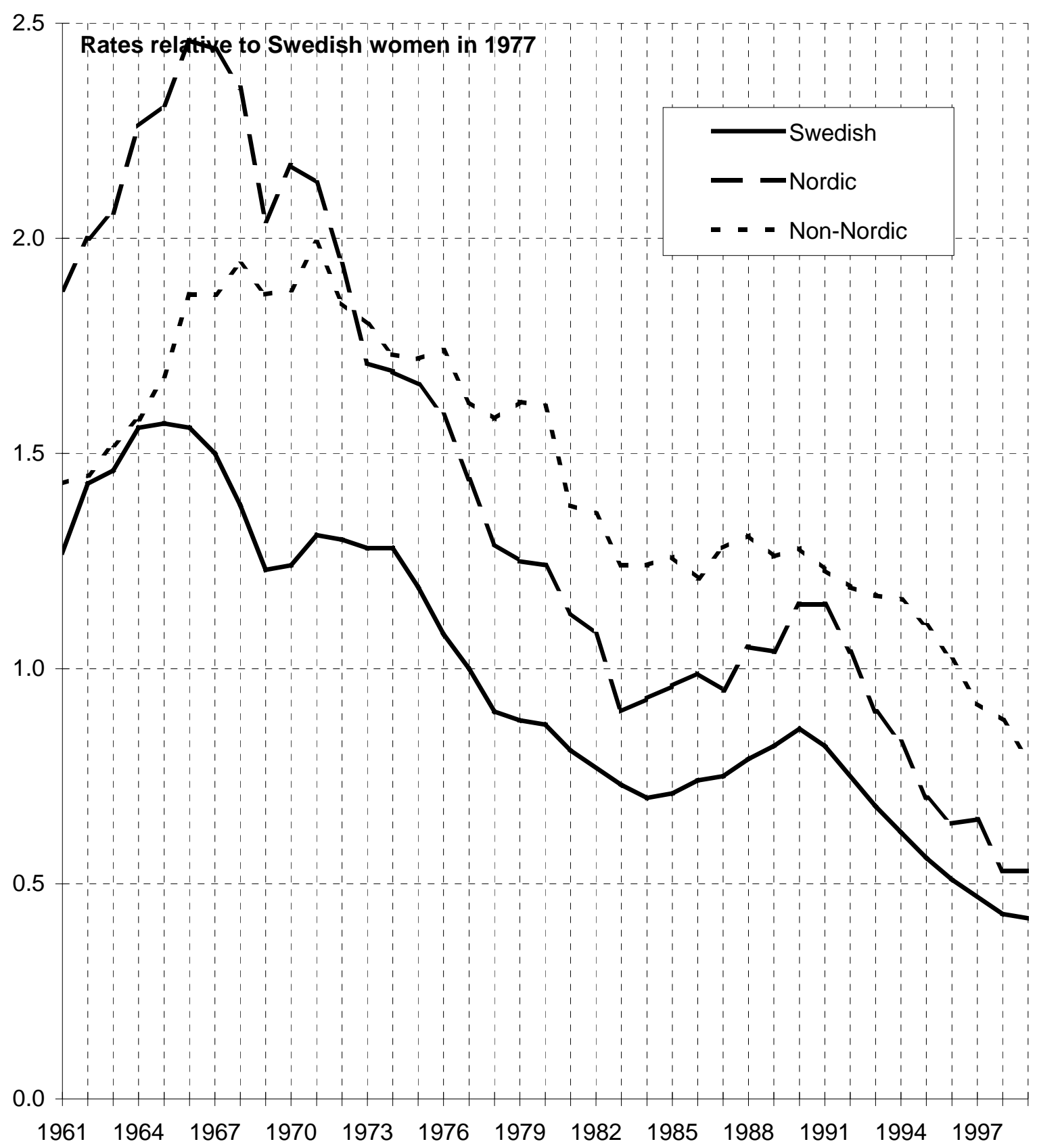


Figure 2: Standardized annual index of first-birth rates. Childless women aged 31-45, 1961-1999, by country-group of origin.

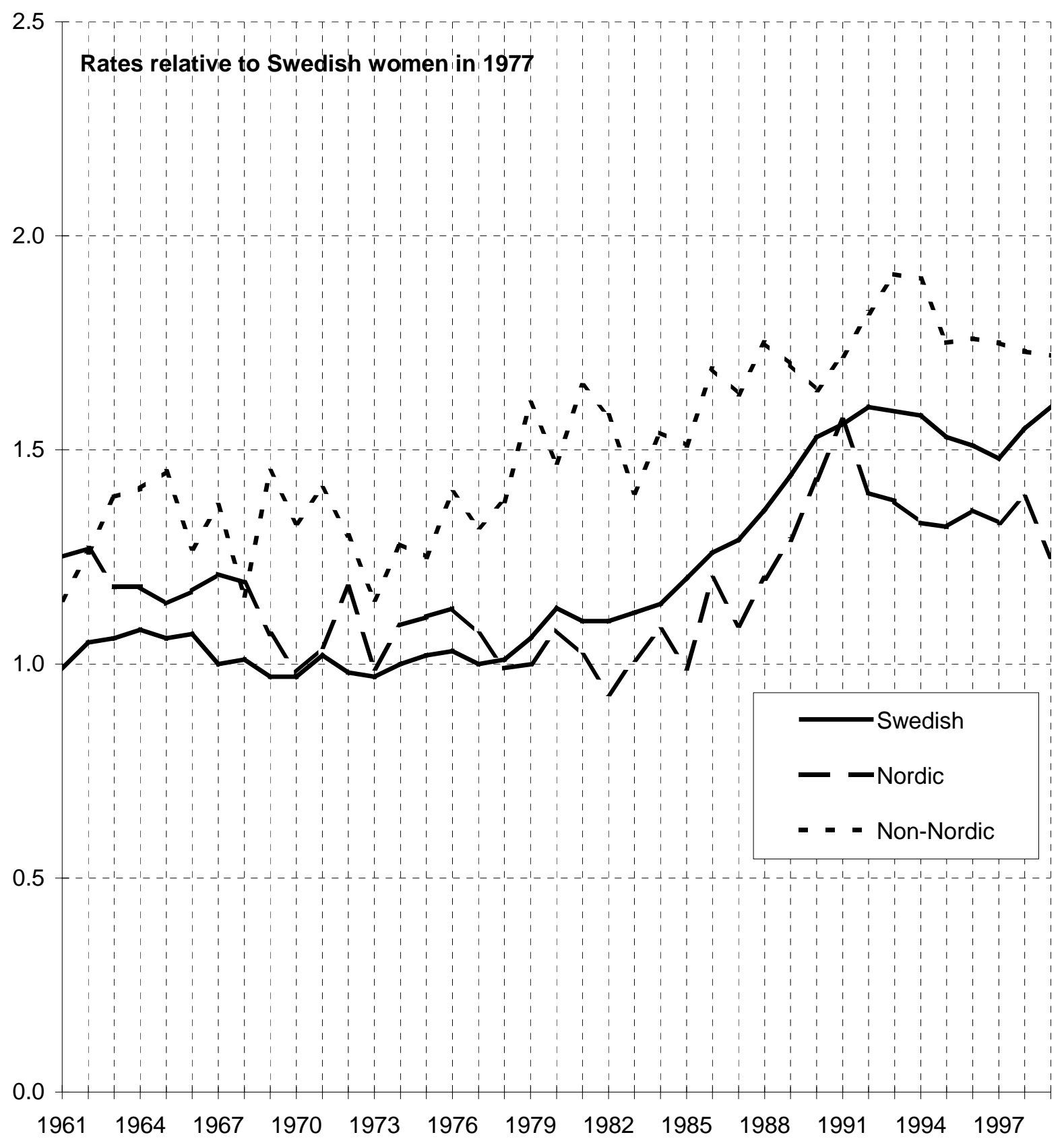


Figure 3: Annual index of second-birth rates. One-child mothers in Sweden, 1961-1999, by country-group of origin, standardized for age of mother and age of first child.

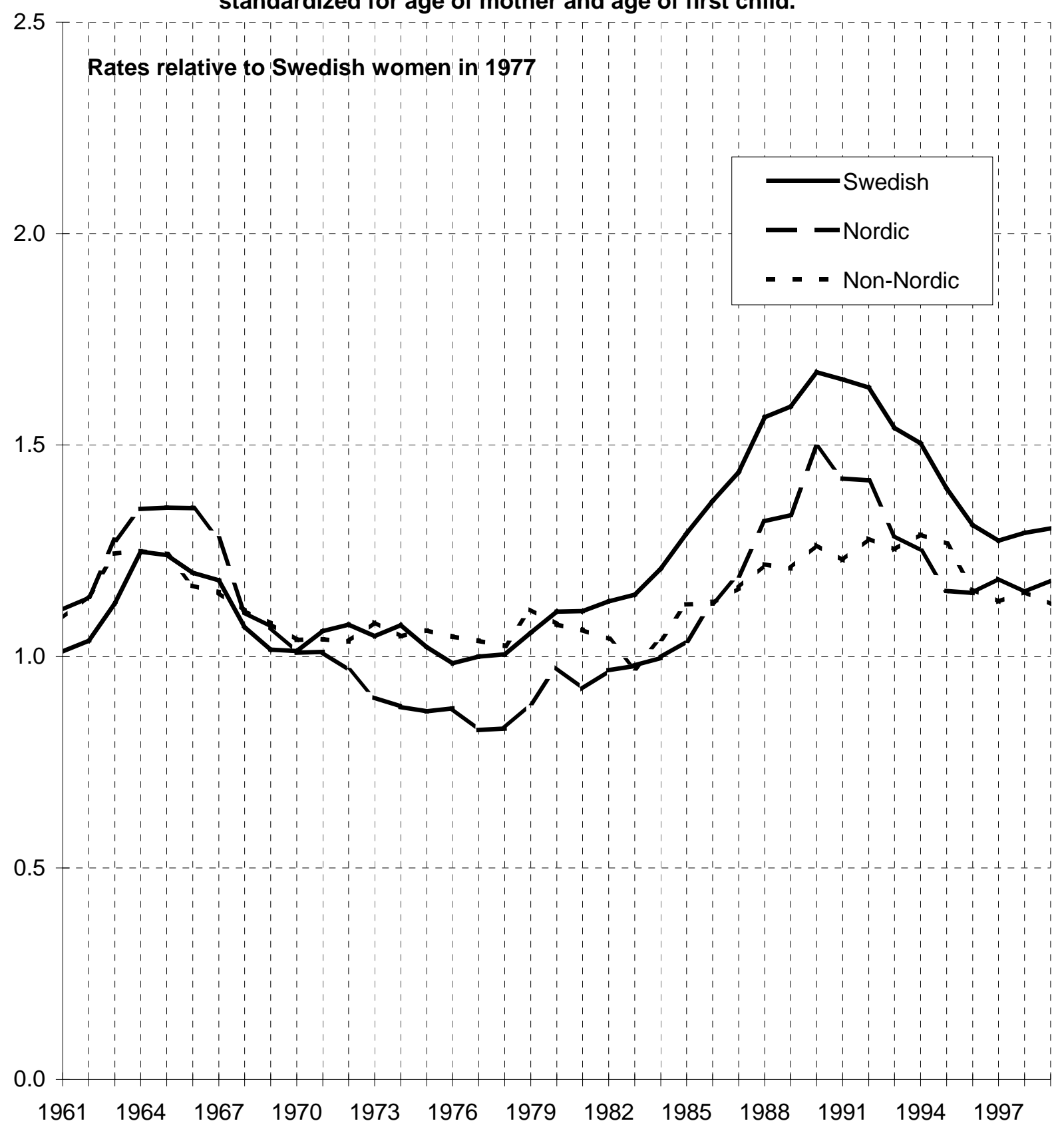


Figure 4: Annual index of third-birth rates. Two-child mothers in Sweden, 1961-1999, by country-group of origin, standardized for age of mother and age of second child.

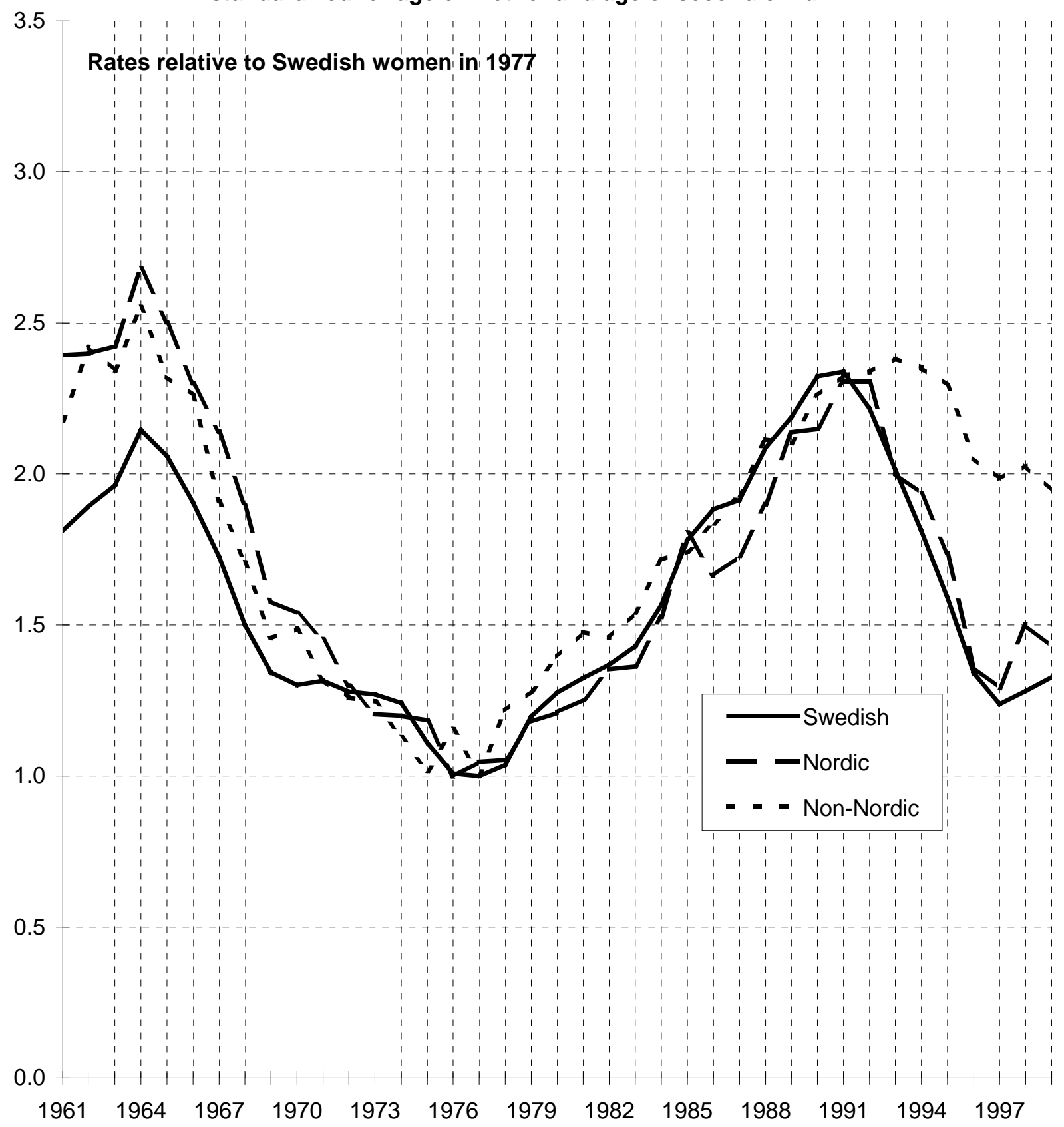


Figure 5: Annual index of fourth-birth rates. Three-child mothers in Sweden, 1961-1999, by country-group of origin,

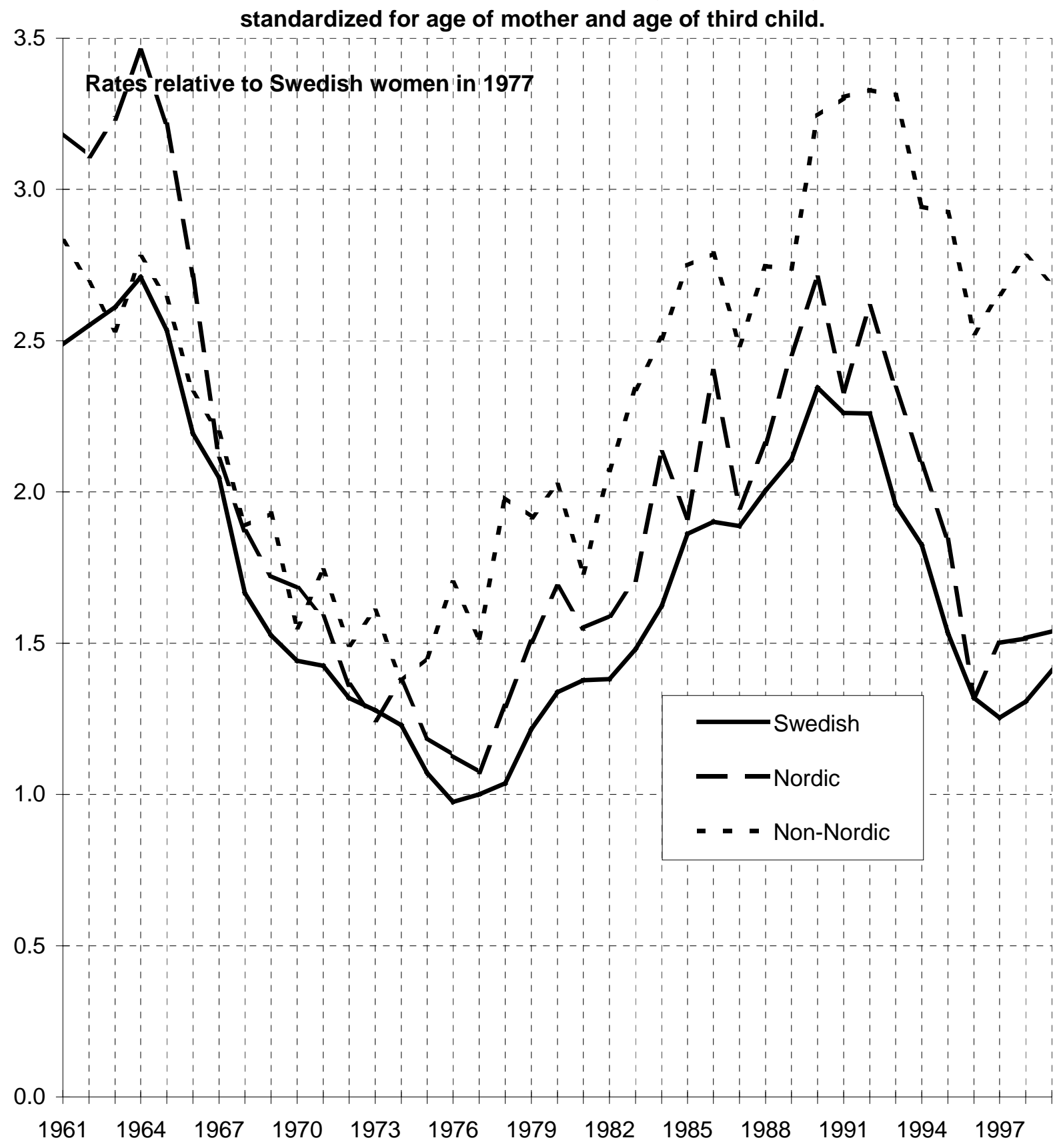

